\title{
Management of osteoporosis in patients hospitalized for hip fractures
}

\author{
T. P. Ip • J. Leung • A. W. C. Kung
}

Received: 18 August 2010 / Accepted: 8 September 2010

(C) The Author(s) 2010. This article is published with open access at Springerlink.com

\begin{abstract}
Hip fracture is associated with high morbidity, mortality, and economic burden worldwide. It is also a major risk factor for a subsequent fracture. A literature search on the management of osteoporosis in patients with hip fracture was performed on the Medline database. Only one clinical drug trial was conducted in patients with a recent hip fracture. Further studies that specifically address post-fracture management of hip fracture are needed. The efficacy of anti-osteoporosis medication in older individuals and those at high risk of fall is reviewed in this paper. Adequate nutrition is vital for bone health and to prevent falls, especially in malnourished patients. Protein, calcium, and vitamin D supplementation is associated with increased hip BMD and a reduction in falls. Fall prevention, exercise, and balance training incorporated in a comprehensive rehabilitation program are essential to improve functional disability and survival. Exclusion of secondary causes of osteoporosis and treatment of coexistent medical conditions are also vital. Such a multidisciplinary team approach to the management of hip fracture patients is associated with a better clinical outcome. Although hip fracture is the most serious of all fractures, osteoporosis management should be
\end{abstract}

T. P. Ip

Department of Medicine, Tung Wah Eastern Hospital,

Hong Kong, China

J. Leung

Department of Medicine, Ruttonjee Hospital,

Hong Kong, China

T. P. Ip · A. W. C. Kung $(\bowtie)$

Department of Medicine, Queen Mary Hospital,

The University of Hong Kong,

Hong Kong, China

e-mail: awckung@hkucc.hku.hk prioritized to prevent deterioration of health and occurrence of further fracture.

Keyword Osteoporosis

\section{Introduction}

A hip fracture that occurs in the context of a low-energy trauma constitutes a fragility fracture. It represents the most serious complication of osteoporosis and the most severe form of osteoporotic fracture. Survival and quality of life decrease significantly following hip fracture and five-year excess mortality increases by about 20\% [1]. Elderly patients with previous history of hip fracture are at very high risk of further fractures: a 2.5 -fold increased risk of vertebral fracture and 2.3-fold risk of future hip fracture [2]. The incidence of hip fracture increases exponentially with age in women between 60 and 85 years, but thereafter more slowly [3]. The vast majority of hip fractures thus occur in elderly individuals, many of them in residential care where the risk of hip fracture is 2 -fold to 11 -fold that of individuals living in the general community [4-8]. Within a year of sustaining a hip fracture, an elderly nursing home resident has a $40 \%$ risk of death and a $6 \%$ to $12 \%$ risk of further hip fracture $[9,10]$ This high incidence of re-fracture is likely related to a very high risk of falls in such individuals: $98 \%$ of hip fractures are the result of fall, the proportion of vertebral fractures is lower [11, 12]. The risk of fracture seems to be determined by a balance between bone strength and propensity for falls, which in term are determined by the frailty of the patient [13].

Hip fractures are easy to diagnose. Thus neither the National Osteoporosis Society (in the UK) nor the National Osteoporosis Foundation (NOF, in the US) 
advises application of the World Health Organization fracture risk assessment tool FRAX for treatment decisions in patients with fragility fracture. The NOF (in the US) advocates drug treatment in such patients without the need for bone mineral density (BMD) measurement, except in young postmenopausal women [14]. The National Osteoporosis Guideline Group of UK recommends BMD measurement in patients aged between 60 and 80 years [15]. It should nonetheless be emphasized that treatment decisions should not be hampered by the unavailability of dual-energy X-ray machines for BMD measurement. A focus on BMD measurement prior to the initiation of anti-osteoporotic treatment in patients with a known history of fracture may result in missed opportunities for treatment. Thus patients with hip fracture and satisfactory quality of life warrant treatment to prevent future fractures. Unfortunately, the proportion of hip fracture patients prescribed with osteoporosis drugs remains low. In a report from Belgium, just $6 \%$ of previously untreated patients hospitalized for hip fractures were prescribed anti-osteoporotic therapy, with only $41 \%$ continuing treatment at 12 months: median treatment duration was 40 weeks [16]. Similarly, in a nationwide survey of 53,325 patients admitted with hip fracture to 318 hospitals in the US, only $6.6 \%$ were prescribed calcium and vitamin $\mathrm{D}$, and $7.3 \%$ anti-resorptive or bone-forming agents [17].

Despite limited data, there is apparently sufficient evidence to support initiation of pharmacological treatment for secondary fracture prevention in hip fracture patients. The objective of osteoporosis treatment is to decrease the risk of re-fracture. Additional benefits include improved quality of life, decreased risk of falls, and reduced mortality. Medical intervention includes non-pharmacological interventions, correction of reversible and secondary causes of bone loss, and anti-osteoporosis medication.

\section{Non-pharmacological prevention of fractures}

\section{Nutrition and protein intake}

Adequate nutrition is vital for bone repair and to prevent further falls but malnutrition is common in older men and women hospitalized for hip fracture [18]. A low score on the Mini-Nutritional Assessment is associated with a twofold increased risk of osteoporosis [19]. The relation between dietary protein intake and bone health is nonetheless controversial: diets high in protein have generally been considered to have adverse effects on bone health because the associated acid load may release calcium from the skeleton and cause bone loss. Darling et al. (2009) recently conducted a systematic review and meta-analysis of both cross-sectional and prospective studies to clarify the relation between dietary protein intake and bone health in healthy adults [20]. No negative relation was identified between dietary protein and bone: there was a slight positive association between increasing dietary protein and BMD. Protein supplementation led to a $1 \%$ to $2 \%$ increase in BMD at the lumbar spine, but there was no strong evidence for a reduced risk of hip fracture. In older individuals with poor oral intake and low protein consumption, a healthy diet that included dairy products (mainly fat free), fruit and vegetables, and adequate amounts of meat, fish, and poultry nonetheless increased insulin-like growth factor I, an enzyme positively related to musculoskeletal health [21]. The Framingham Osteoporosis Study studied 946 elderly men and women and observed that individuals with a protein intake at the upper quartile had a $37 \%$ decreased risk of hip fracture [22]. Data from large prospective studies are nevertheless needed to confirm this finding. Although the effect on fracture prevention is controversial, a balanced diet with adequate protein intake can prevent weight loss, muscle wasting, and sarcopeniaimportant risk factors for frailty and falls.

\section{Calcium and vitamin D supplementation}

Vitamin D deficiency or insufficiency is common in the elderly hip fracture patients. Vitamin D is rare in food. The major source of Vitamin D is synthesis of cholecalciferol (Vitamin D3) from its precursors in the skin under the effect of ultraviolet light. Vitamin D insufficiency is more prevalent in older subjects due to less efficient synthesis of Vitamin D3 in the skin [23], decreased renal production of 25OHD [24] and decreased gastrointestinal absorption of calcium in response to $1,25 \mathrm{OHD}$ [25].

Vitamin D deficiency is defined in the presence of osteomalacia $(25 \mathrm{OHD}<25 \mathrm{nmol} / \mathrm{L})$, while insufficiency is defined as the occurrence of secondary hyperparathyroidism with $25 \mathrm{OHD} 25$ to $50 \mathrm{nmol} / \mathrm{L}$ [26]. The optimal serum $25(\mathrm{OH}) \mathrm{D}$ is 50 to $80 \mathrm{nmol} / \mathrm{L}$ [27]. The prevalence of vitamin D insufficiency and suboptimal serum 25(OH)D among the older population is around $30-50 \%$ in most parts of the world [28-31].

Vitamin D is the key to intestinal absorption of calcium, and hence ensuring calcium and vitamin D sufficiency forms a pivotal part of the fracture prevention management protocol. Calcium and vitamin D supplementation improves bone mineralization, reduces bone resorption, corrects secondary hyperparathyroidism and prevents falls [26]. There is also evidence that calcium and vitamin D enhance the anti-fracture efficacy of bisphosphonate agents. Of note, patients in pivotal studies of all anti-osteoporotic agents received calcium and vitamin D supplementation. Thus calcium and vitamin D supplementation is a key component 
in the prevention and treatment of osteoporosis unless calcium intake and vitamin D status are known to be optimal.

The difficulty in interpreting studies on the use of calcium and vitamin D for fracture prevention is related to the heterogeneity of studies in terms of study population, treatment doses, preparations, and combinations, baseline calcium and vitamin D intake, baseline 25OHD levels, and compliance with treatment.

A number of randomized clinical trials have attempted to determine the effect of vitamin D and calcium on fracture prevention. Early studies performed among institutionalized subjects with a mean age of 84 years showed that use of daily vitamin D3 $800 \mathrm{IU}$ and 1,200 $\mathrm{mg}$ calcium resulted in a significant reduction in hip fracture with a relative risk of $43 \%$ [32]. In contrast, community-based randomized controlled clinical trials that recruited patients with $>1$ risk factor for fracture [33] or a history of low-trauma fracture [34] with a mean age of 77 years, and supplemented with daily vitamin D3 $800 \mathrm{IU}$ and calcium 1,000 mg demonstrated no reduction in hip fractures or total fractures. Nonetheless the hip fracture rate was noted to be low for the two studies: $<1 \%$ for all groups [33] and $4 \%$ overall [34]. In addition, in the Women's Health Initiative study of elderly women (mean age 66 years old) who were randomized to receive daily vitamin D3 $400 \mathrm{IU}$ and calcium $1,000 \mathrm{mg}$, there was no reduction in hip fracture rate with hazard ratio of 0.88 (95\% CI 0.72,1.08) [35].

A meta-analysis, employing a random effect model and involving 63,897 subjects (mean age of $67.8 \pm 9.7$ years) revealed that calcium supplementation with or without vitamin $\mathrm{D}$ was associated with a $12 \%$ risk reduction in fractures of all types $(95 \%$ CI $0.83,0.95)$ [36]. The treatment effect was better in institutionalized than in community-dwelling subjects (RR 0.76 vs 0.94), those with low daily calcium intake $(<700 \mathrm{mg}$ /day) and older age $>70$ years. The estimated number needed to treat (NNT) to prevent one fracture was 63. Another systematic review that employed a fixed effect model demonstrated that a combination of Vitamin D and calcium resulted in an overall reduction in hip fracture with risk ratio of $0.84(95 \%$ CI $0.73,0.96)$. Risk ratio was lower for institutionalized than community-dwelling subjects (0.75 vs 0.91) [37]. Another meta-analysis that employed a random effect model and involved 9,083 subjects demonstrated that combined vitamin $\mathrm{D}$ and calcium could reduce hip fracture incidence by $25 \%(95 \%$ CI 4,42$)$. The estimated NNT to prevent one fracture was approximately 276 [38]. In addition, two meta-analyses revealed that use of Vitamin D alone in comparison with placebo did not result in hip fracture reduction $[37,38]$.

Better compliance results in better risk reduction of total or hip fracture. In a meta-analysis, studies with $>80 \%$ compliance resulted in a doubling of risk reduction, $24 \%$ vs $12 \%$ of total fractures [36]. In the Women's Health Initiative (WHI) study, analysis of data excluding followup time for subjects 6 months following detection of noncompliance showed an increase in risk reduction of hip fracture by $29 \%$ (versus $12 \%$ when using ITT analysis) [35].

The minimal level of serum 25OHD for fracture prevention is considered to be 30 to $80 \mathrm{nmol} / \mathrm{L}$, and supplementation with Vitamin D is recommended to be 800 to $1,000 \mathrm{IU}$ per day to achieve a serum $25 \mathrm{OHD}$ level of $75 \mathrm{nmol} / \mathrm{L}$ [26]. A meta-analysis showed that vitamin D may have a dose-dependent effect: pooling trials with a higher received dose of $>400 \mathrm{IU} /$ day, heterogeneity of the studies was resolved and a relative reduction in hip fracture of $18 \%$ was demonstrated $(95 \%$ CI, 0.69-0.97) [39]. Analysis also showed that for both hip and non-vertebral fractures, the anti-fracture efficacy increased significantly with a higher received dose (metaregression: $\beta=-0.001 ; P=.07$ ) and higher achieved 25-hydroxyvitamin D levels (metaregression: $\beta=-0.009$; $P=.01)$. The received dose of vitamin $\mathrm{D}$ was determined from cross-product of dose and percentage compliance with supplementation.

Most studies of calcium supplementation prescribe a daily calcium dose of 1,000-1,200 $\mathrm{mg}$ [32-35]. In contrast to vitamin D supplementation, meta-analysis of prospective cohort studies and clinical trials did not show a higher fracture risk reduction with a higher calcium intake [40]. In addition, a randomized controlled trial of elemental calcium supplementation at a dose of $1,000 \mathrm{mg} /$ day showed an increase in relative risk of $47 \%$ (95\% CI $0.97,2.23$ ) in combined cardiovascular endpoints (defined as sudden death, myocardial infarction, angina, or chest pain) when compared with placebo [41]. In the WHI study, those who received calcium $1,000 \mathrm{mg}$ daily had a $17 \%$ increase in the incidence of renal stones or renal insufficiency compared with placebo group [35]. At present, the exact calcium requirement remains a matter for debate although a total daily calcium intake (diet plus supplementation) of approximately $1,000 \mathrm{mg} /$ day is likely to be sufficient and safe.

Relationship between vitamin D, falls and fracture prevention

Approximately $5 \%$ to $10 \%$ of all falls will result in a fracture and $90 \%$ of all fractures are results of falls [42, 43]. A low level of vitamin D is associated with an increased incidence of falls in the elderly [44, 45]. Possible mechanisms include the effect of vitamin D on calcium homeostasis, muscle strength [46], and physical performance $[47,48]$. An increased risk of fall occurs when 25 
(OH)D falls below $25 \mathrm{nmol} / \mathrm{L}$ [49]. Body sway is also noted to increase when $25(\mathrm{OH}) \mathrm{D}$ falls below $50 \mathrm{nmol} / \mathrm{L}$ [50]. Lower limb physical performance declines markedly when serum 25(OH)D falls below $50 \mathrm{nmol} / \mathrm{L}$ [47].

Interestingly, systematic review demonstrates that use of vitamin $\mathrm{D}$, alone or in combination with calcium, does not significantly reduce falls (both rate of falls or number of fallers) or incidence of fracture following fall [51]. Nonetheless, subgroup analysis reveals that falls can be reduced in those with low-baseline $25(\mathrm{OH}) \mathrm{D}$ level with risk ratio of $0.57(95 \%$ CI $0.37,0.89)$ compared with those with high-baseline $25(\mathrm{OH}) \mathrm{D}$ and risk ratio of $1.02(95 \%$ CI, 0.88,1.19) [51]. Another meta-analysis of pooled data from seven randomized controlled trials that recruited 1,921 subjects demonstrated that use of Vitamin D 700 1,000 IU daily could reduce falls with a risk ratio of 0.81 $(95 \%$ CI $0.71,0.92)$. In addition, subjects who achieved a $25(\mathrm{OH}) \mathrm{D}$ level $>60 \mathrm{nmol} / \mathrm{L}$ had reduced falls with a risk ratio of 0.77 (95\% CI $0.65,0.90)$, compared with those with level $<60 \mathrm{nmol} / \mathrm{L}$ and risk ratio of $1.35(95 \% \mathrm{CI}$ $0.98,1.84)$ [52].

It is known that vitamin $\mathrm{D}$ is stored in fat and that the half life of $25(\mathrm{OH}) \mathrm{D}$ is 3 weeks. Thus vitamin $\mathrm{D}$ supplementation can be given every month or 4 to 6 months. Clinical study demonstrates a reduction in total fracture following prescription of 100,000 IU vitamin D orally every 4 months in community-dwelling subjects with a relative risk of $0.78(95 \% \mathrm{CI}, 0.61,0.99)$ [53]. A yearly regimen was noted to be undesirable. Another study that administered vitamin D2 300000 IU by intramuscular injection during the autumn did not result in reduction in relative risk of first fracture, but significantly increased the risk of first hip fracture [54]. A recent study of oral vitamin D 500,000 given yearly during autumn or winter to the elderly with mean age 76 years old, for a median follow-up of around 3 years, demonstrated that the active group had an increased incidence of fractures with relative risk of 1.26 $(95 \%$ CI $1.00,1.59)$ and also an increased incidence of falls with relative risk of 1.15 (95\% CI 1.02, 1.30) [33]. Of interest, there was an increased incidence of fractures and falls in the first 3 months after yearly oral intake compared with month 4 to12 months [55].

Vitamin D metabolites including 1-alpha cholecalciferol (alphacalcidol) and 1,25-dihydroxycholecalciferol (calcitriol) are used in some Asian countries with positive results on hip fracture prevention, although the studies are small and the effect on BMD improvement is controversial [56, 57]. The effect on fracture reduction is partly mediated by a reduced incidence of falls because of improved muscle strength and neuromuscular coordination. These agents nonetheless increase intestinal calcium absorption pharmacologically and have a low margin of safety with a risk of hypercalcaemia and hypercalciuria.

\section{Pharmacological management: consideration in hip fracture patients}

Currently available anti-osteoporosis therapies include hormone therapy (HT), calcitonin, selective estrogen receptor modulators (SERMs), bisphosphonates, parathyroid hormone $(\mathrm{PTH})$, and strontium ranelate. HT and calcitonin have become unpopular in the last 10 years: HT imposes an unnecessary health risk to postmenopausal women especially in older women [58], and calcitonin has inconsistent or uncertain anti-fracture efficacy, especially for non-vertebral fractures [59].

Most randomized controlled studies of anti-osteoporosis drugs have not focused on hip fracture patients, partly because they tend to be frail elderly who constitute a challenge in terms of study design. The inclusion criteria have been generally based on a history of vertebral fracture and/or a BMD that fulfills the World Health Organization (WHO) working definition of osteoporosis. In this context, despite the availability of a wide spectrum of antiosteoporosis drugs, there is a significant paucity of evidence-based literature to guide treatment of this older patient population with hip fracture.

\section{Efficacy of anti-osteoporosis drugs in patients with hip fracture}

The most compelling evidence to support anti-osteoporosis treatment in hip fracture patients comes from zoledronic acid, a bisphosphonate. The Health Outcomes and Reduced Incidence with Zoledronic Acid Once Yearly (HORIZON) Recurrent Fracture Trial (RFT) was a secondary prevention study that involved 1,065 subjects ( $75 \%$ women) with mean age $75 \pm 9$ years and incidental hip fracture. Zoledronic acid at a dose of $5 \mathrm{mg}$ administered as a yearly 15 -minute intravenous infusion with the first dose being given within 90 days after hip fracture surgery significantly reduced any new clinical fracture by $35 \%$, clinical vertebral fracture by $46 \%$ and non-vertebral fracture by $27 \%$ after a mean follow-up of 1.9 years. Risk of hip fracture was reduced by $30 \%$ but this was not significant due to the low number of events [60]. There was also a significant $28 \%$ reduction in all-cause mortality in the active treatment group [60]. Though the exact underlying mechanism responsible for this improved survival has yet to be elucidated, an exploratory analysis showed that zoledronic acid-treated subjects were less likely to die from pneumonia and arrhythmias than placebo-treated subjects [61].

A pivotal study of Zoledronic acid, the HORIZON Pivotal Fracture Trial, that involved 3,889 postmenopausal osteoporotic women with a mean age of $73 \pm 5$ years $(38 \%$ were $>75$ years of age) also showed a significant $70 \%$ 
reduction in the incidence of morphometric vertebral fracture, a $25 \%$ reduction in non-vertebral fracture, and a $41 \%$ reduction in hip fracture at 36 months [62]. Subgroup analysis in subjects aged $\geq 75$ years was not available.

Significant anti-fracture efficacy at the spine in the elderly population was also evident for two other bisphosphonates, alendronate, and risedronate. Pooled analysis of the combined data of 1,392 women $\geq 80$ years of age (mean age $83 \pm 3$ years) from the three major phase three clinical trials of risedronate showed that risedronate $5 \mathrm{mg}$ daily significantly reduced the risk of new vertebral fracture by $81 \%$ at 1 year and $44 \%$ at 3 years. The NNT were 12 and 16 after 1 and 3 years, respectively. The reduction in risk of non-vertebral fracture was nonetheless not significant at either time point [63].

In a subgroup analysis of 539 women aged $\geq 75$ years (range 75-82 years) in the Fracture Intervention Trial, alendronate significantly reduced new vertebral fracture by $38 \%$ at 3 years. The corresponding NNT was 13. Data on non-vertebral fracture reduction were unavailable [64].

Agents with bone-forming properties, teriparatide and strontium ranelate, have also shown evidence of fracture risk reduction in older patients. A pre-planned analysis of the pooled data of 1,488 women $80-100$ years of age from the SOTI and Treatment of Peripheral Osteoporosis (TROPOS) studies showed that strontium ranelate at a dose of $2 \mathrm{~g}$ daily achieved a significant $59 \%$ risk reduction in vertebral fracture, $41 \%$ risk reduction in non-vertebral fracture, and $37 \%$ risk reduction in clinical fracture at 1 year. The corresponding risk reductions were $32 \%, 31 \%$, and $21 \%$, respectively, at 3 years [65]. In the TROPOS study, strontium ranelate additionally showed a significant $36 \%$ risk reduction in hip fracture at 3 -years in a post-hoc analysis of a high-risk subgroup of women with age $\geq 74$ years and femoral neck BMD T-score $<-3$ [66].

In a pre-specified subgroup analysis of the Fracture Prevention Trial (FPT), teriparatide demonstrated a 59\% reduction in risk of new vertebral fracture at 1 year in 244 women with age $\geq 75$ years (range $75-86$ years) and $\geq 1$ moderate vertebral fracture or two mild vertebral fractures at baseline. The risk reduction in non-vertebral fracture was nonetheless not significant [67]. Since the FPT was terminated early with median treatment duration of 19 months, longer-term data on fracture risk reduction are unavailable [67].

The SERM, raloxifene, has not demonstrated a positive effect on non-vertebral fracture reduction in clinical studies [68] and its anti-fracture efficacy at the spine in the older age group has not been adequately addressed. The newer SERM, bazedoxifene, at a dose of $20 \mathrm{mg}$ daily has shown a significant $50 \%$ risk reduction in non-vertebral fracture at 3 years in a post-hoc analysis of a higher-risk subgroup of 1,772 women with femoral neck T-score $\leq-3.0$ and/or $\geq 1$ moderate or severe vertebral fracture or multiple mild vertebral fractures [69]. The age of this higher-risk subgroup was not specified.

Denosumab, a fully human monoclonal antibody that specifically binds to the receptor activator of nuclear factorkappa B ligand (RANKL) was recently developed as a new anti-resorptive agent with a novel mechanism of action. Given as a subcutaneous injection at a dose of $60 \mathrm{mg}$ every 6 months for 36 months in the FREEDOM trial, denosumab significantly reduced the risk of new radiographic vertebral fracture by $68 \%$, the risk of hip fracture by $40 \%$ and the risk of nonvertebral fracture by $20 \%$ in 7,868 postmenopausal osteoporotic women of age 60 to 90 years [70]. Whether this potent anti-resorptive agent will have specific benefit to the elderly or hip fracture patients requires further study.

In conclusion, although hip fracture is the most common fracture in patients who live beyond their $70 \mathrm{~s}$, there is limited evidence to guide treatment of osteoporosis in these patients. Nonetheless, it is reasonable to prescribe antiosteoporosis drugs to such high-risk patients based on the assumption that they will respond to treatment in a similar manner to other more well-defined groups of osteoporotic patients in clinical trials, who are of younger age with or without prior vertebral fracture. Zoledronic acid appears to be the only agent that demonstrates both vertebral and nonvertebral fracture risk reduction as well as survival benefit in the fracture hip population. With regards general antifracture efficacy in the elderly, risedronate, strontium ranelate, and teriparatide all provide evidence of early risk reduction of vertebral fracture at 1 year with benefits sustained to 3 years for risedronate and strontium ranelate. Alendronate provides evidence of vertebral fracture risk reduction at 3 years only. Anti-fracture efficacy at nonvertebral sites was only provided by strontium ranelate at both time points in women aged $\geq 80$ years.

\section{Effect of anti-osteoporosis drugs on fracture healing}

Whether fracture healing is affected or not by antiosteoporosis treatment is one of the most important concerns of the orthopedic surgeon, in particular with regard to bisphosphonates that suppress bone-turnover. Animal models of fracture demonstrate that bisphosphonates delay remodeling of callus, which became larger in size but stronger in structural strength [71, 72]. Raloxifene and estrogen have no major effect on fracture healing [72].

Well-designed randomized clinical trials in humans to address this important issue are lacking. A small cohort study that compared radiographic fracture healing of the distal radius in 43 patients prescribed bisphosphonate therapy at the time of fracture with 153 control subjects revealed that bisphosphonate use was associated with a longer time to 
radiographic union $(55 \pm 17$ days vs $49 \pm 14$ days). The differences in healing time were nonetheless small $(<1$ week) and considered clinically insignificant [73].

The best reassuring piece of clinical evidence in hip fracture patients is provided again by the HORIZON RFT in which zoledronic acid infusion was given within 90 days of hip fracture repair. The incidence of delayed union was 34 $(3.2 \%)$ in the zoledronic acid group and $29(2.7 \%)$ in the placebo group (risk ratio $1.17 ; 95 \%$ CI $0.72-1.90 ; P=0.61$ ) [60]. There was no clinical evidence of impaired facture healing with early administration of a potent bisphosphonate.

For bone-forming agents, teriparatide, by virtue of its stimulatory effect on bone formation, has been reported to accelerate remodeling, improve material properties, and enhance fracture healing in animal models [74-76]. Strontium ranelate also significantly increases bone formation, BMD, biomechanical strength, and improves microstructural properties of the callus in a rat model [77]. A direct comparison study using an osteoporotic rat model of fracture healing showed that strontium ranelate enhances callus strength more than teriparatide [78].

Although findings in animal models cannot be extrapolated to humans, there appear to be no suggestions of a negative effect on fracture healing with anti-osteoporosis drug treatment. In a recent multidisciplinary workshop of the International Society for Fracture Repair, leading experts carried out an extensive review of the literature and reached a consensus that there is no evidence-based reason to withhold anti-resorptive therapy while a fracture heals, whether or not the patient is taking such therapy when the fracture occurs [79]. It recommended that secondary prevention should be implemented as soon as possible after a fragility fracture and at least prior to discharge from an acute fracture ward [79].

This consensus has vital clinical implications in the management of patients with fracture. Currently, the majority of patients with a history of fracture fail to receive effective anti-osteoporosis treatment for secondary prevention [80] and of those who have been treated with oral bisphosphonates, the rate of adherence to therapy is very suboptimal with an overall 1-year persistence rate ranging from $17.9 \%$ to $78.0 \%$ despite the use of more convenient weekly preparations [81]. The acute presentation of patients with fragility fracture, notably hip fracture, should provide a great opportunity for clinicians to commence secondary prevention at this important "signal" fracture stage, which may improve persistence and compliance with treatment.

\section{Effect of anti-osteoporosis drugs on survival}

Hip fractures are associated with the highest degree of morbidity and mortality of all fractures with an associated 1-year mortality up to $15-25 \%$. The HORIZON RFT was the first study in the literature to show a reduction in mortality when anti-osteoporosis drug therapy was commenced following a hip fracture. There was a $28 \%$ reduction in mortality in the active treatment group after a mean follow-up of 1.9 years [60]. An exploratory analysis showed that its impact on mortality was mediated only to a small extent (8\%) through its fracture reduction benefit and zoledronic acid-treated subjects were less likely to die from pneumonia and arrhythmias than placebo-treated subjects [61]. The mechanism for this finding is currently unknown but may relate to the anti-inflammatory, anti-angiogenic, and immuno-modulatory effects of bisphosphonates [61].

Since the individual trials of other anti-osteoporosis drugs were not powered to detect mortality difference, a meta-analysis of $>40,000$ subjects in ten placebo-controlled randomized studies of five agents (alendronate, risedronate, strontium ranelate, zoledronic acid, and denosumab) was performed. Results showed that treatment of osteoporosis was associated with a significant $10 \%$ reduction in mortality [82]. A $10 \%$ relative risk reduction corresponds to an absolute mortality benefit ranging from 0.4 to seven deaths prevented per 1,000 patient-years of treatment. This mortality reduction was mainly observed in studies of older, frailer individuals at high risk of fracture [82]. The consolidation of a survival benefit from treatment of osteoporosis and the absence of a negative effect on fracture healing should further encourage early antiosteoporosis drug treatment in patients with hip fracture.

\section{Exclusion of secondary causes for osteoporosis}

All patients with fracture should be carefully evaluated to exclude secondary osteoporosis. Such evaluation should include a thorough history, physical examination, bone mineral density testing, and laboratory testing. While there is no consensus on the most cost-effective laboratory evaluation, general recommendations include measurement of serum 25-hydroxyvitamin D, PTH, complete blood count, serum and urine calcium, phosphate, renal and liver function tests, thyroid-stimulating hormone, and testosterone in men.

Vitamin D insufficiency is a common cause of bone loss in the elderly. Approximately $50 \%$ of men with osteoporosis have an underlying risk factor for bone loss [83]. Apart from the well-recognized association with glucocorticoids, an increasing list of drugs has been implicated in bone loss and fractures. Osteoporosis related to hormonal deprivation therapy such as anti-androgenic therapy for prostate cancer and aromatase inhibitor therapy for breast cancer is an important area that has been overlooked in the past. Clinicians have a significant responsibility to evaluate and 
treat any underlying medical problem that causes bone loss and to optimize bone health in the individual patient. With appropriate consideration of secondary causes and relevant investigations and newer therapies, many of these conditions can be prevented.

\section{Treatment of pre-existing medical problems}

Pre-existing medical problems are often the facilitating factors for fractures and important determinants for morbidity, mortality, and final outcome in patients with hip fracture. Cardiopulmonary and neurological disorders are the most frequent medical diseases in these elderly hip fracture patients. The presence of ischemic heart disease, heart failure, cardiac arrhythmia, hypertension, chronic obstructive airways disease, pneumonia, or cerebrovascular disease confer the most risk for complications and difficulties during anesthesia, surgery, immediate postoperative recovery, and rehabilitation. Other major diseases include diabetes, cataract, dementia, depression, and psychosis. Adopting a multidisciplinary approach to management with consequent attention to these conditions during the perioperative period may reduce postoperative complications and mortality. A meta-analysis of nine studies that involved 4,637 patients demonstrated lower odds of deep venous thrombosis, pressure ulcer, surgical site infection, and urinary tract infection in patients managed according to clinical pathways than in those receiving usual care [84].

\section{Preventing frailty and falls}

Non-pharmacological therapies consist of education about osteoporosis and fracture prevention; lifestyle advice and modifications; optimization of nutritional, calcium and vitamin D intake; fall preventive measures. There is evidence that a multidisciplinary approach to the care of patients with hip fracture is associated with a higher pickup rate of treatment and significantly lower re-fracture and mortality rates [85]. Over $98 \%$ of hip fractures are associated with falls and fall has been consistently shown to be one of the most important underlying risk factors. A pro-active approach to prevent falls should receive at least as much attention as drug therapy for osteoporosis in hip fracture patients, but is often an area of care that is neglected. The concept of frailty has received increasing attention in recent years as neither BMD nor clinical risk factors such as age and weight can capture fully the risk of osteoporotic fractures in elderly. Frailty is a state of poor well being, related to muscle weakness and sarcopenia, poor endurance, a low level of physical activity and easy exhaustion and with a slowness of gait [86]. Physical activity and exercise form part of the post-hip fracture rehabilitation but in the elderly, also serve to increase muscle mass and strength, improve body function, reduce risk of fall, and contribute to a better quality of life. Immobilization accelerates bone loss and should be avoided as far as possible. Nonetheless the minimal level of physical activity and exercise required to prevent bone loss remains a matter for debate [87]. Exercises that improve balance, including Tai-Chi, reduce the incidence of falls and fall-related injuries in community-dwelling, physically inactive individuals of mean age 77 years [88] but do not reduce the risk of fracture. In a meta-analysis of four studies that involved community-dwelling individuals aged 65 to 97 years, a home exercise training program reduced falls and fall-related injuries, with the effect being more pronounced in participants aged 80 years and above [89]. In hip fracture patients with reduced mobility and poor balance, careful evaluation is required before exercise is prescribed: without adequate balance training the subject may be at higher risk of falls and hence fractures.

In post-hip fracture subjects with poor mobility, poor motivation, and easy fatigability, whole-body vibration is a potential promising alternative to conventional exercise. Whole-body vibration can induce gain in muscle strength similar to that achieved with conventional resistance training. It also improves BMD in postmenopausal women [90]. Data on fall prevention and reduction in fracture risk are as yet unavailable. The benefit of wearing hip protectors in hip fracture prevention is controversial as patient compliance is often a problem and study results thus unreliable. Recent systemic review and meta-analysis failed to confirm the effect of hip protectors in communitydwelling subjects or nursing home residents [91, 92].

Medical risk factors that predispose the elderly to fall should be identified and treated. These include correction of cataract and other causes of visual impairment, evaluation of gait and balance, and avoidance of sedatives or medications that may affect balance and stability. Elderly individuals who are physically unstable should be prescribed appropriate walking aids and gait-training exercises. Assessment of home and environmental safety is often neglected and should be emphasized. In individuals who require assistance with daily activities, care-providers should be educated on the correct technique in the transfer of elderly to avoid fall and fall-related injuries.

\section{Conclusion}

Hip fracture is a major problem in the elderly population that creates a huge medical and economic burden worldwide. Patients with hip fractures are at high risk of future fracture and proper management is vital to reduce the 
associated impact on quality of life and mortality and to prevent the risk of future fractures.

Very few studies have investigated the anti-fracture efficacy of osteoporosis medication in patients with hip fractures, and more data are required to better define their optimal treatment. Non-pharmacological treatment, including adequate nutrition, calcium, and vitamin D intake together with exercise and rehabilitation programs form a vital part of the treatment regimen in these frail elderly patients. Recent data suggest that a multidisciplinary team that provides holistic evaluation and medical care before and after surgery and throughout the rehabilitation process is associated with a better patient outcome. Although hip fracture is the most serious complication of osteoporosis, active implementation of appropriate treatment can provide better outcome in terms of survival and re-fracture rates.

\section{Conflicts of interest None.}

Open Access This article is distributed under the terms of the Creative Commons Attribution Noncommercial License which permits any noncommercial use, distribution, and reproduction in any medium, provided the original author(s) and source are credited.

\section{References}

1. Cooper C, Atkinson EJ, Jacobsen SJ, O'Fallon WM, Melton LJ 3rd (1993) Population-based study of survival after osteoporotic fractures. Am J Epidemiol 137(9):1001-1005

2. Klotzbuecher CM, Ross PD, Landsman PB, Abbott TA 3rd, Berger M (2000) Patients with prior fractures have an increased risk of future fractures: a summary of the literature and statistical synthesis. Bone Miner Res 15(4):721-739

3. Couris CM, Duclos A, Rabilloud M, Couray-Targe S, Ecochard R, Delmas PD, Schott AM (2007) A seventy percent overestimation of the burden of hip fractures in women aged 85 and over. Bone 41(5):896-900

4. Cumming RG (1996) Nursing home residence and risk of hip fracture. Am J Epidemiol 143(12):1191-1194

5. Brennan nee Saunders J, Johansen A, Butler J, Stone M, Richmond P, Jones S, Lyons RA (2003) Place of residence and risk of fracture in older people: a population-based study of over 65-year-olds in Cardiff. Osteoporos Int 14(6):515-519

6. Ooms ME, Vlasman P, Lips P, Nauta J, Bouter LM et al (1994) The incidence of hip fractures in independent and institutionalized elderly people. Osteoporos Int 4(1):6-10

7. Norton R, Campbell AJ, Reid IR, Butler M, Currie R, Robinson E, Gray H (1999) Residential status and risk of hip fracture. Age Ageing 28(2):135-139

8. Butler M, Norton R, Lee-Joe T, Cheng A, Campbell AJ (1996) The risks of hip fracture in older people from private homes and institutions. Age Ageing 25(5):381-385

9. Papaioannou A, Wiktorowicz M, Adachi JD, Goeree R, Papadimitropoulos E et al (2000) Mortality, independence in living, and re-fracture, one year following hip fracture in Canadians. J Soc Obstet Gynaecol Can 22:591-597
10. Berry SD, Samelson EJ, Ngo L, Bordes M, Broe KE, Kiel DP (2008) Subsequent fracture in nursing home residents with a hip fracture: a competing risks approach. J Am Geriatr Soc 56 (10):1887-1892

11. Parkkari J, Kannus P, Palvanen M, Natri A, Vainio J, Aho H, Vuori I, Järvinen M (1999) Majority of hip fractures occur as a result of a fall and impact on the greater trochanter of the femur: a prospective controlled hip fracture study with 206 consecutive patients. Calcif Tissue Int 65(3):183-187

12. Cooper C, Atkinson EJ, O'Fallon WM et al (1992) Incidence of clinically diagnosed vertebral fractures: a population-based study in Rochester, Minnesota, 1985-1989. J Bone Miner Res 7:221-227

13. Bergman H, Ferrucci L, Guralnik J et al (2007) Frailty: an emerging research and clinical paradigm - issues and controversies. J Gerontol A Biol Sci Med Sci 62:731-737

14. NOF's Clinician's Guide to Prevention and Treatment Osteporosis. ww.nof.org

15. Compston J, Cooper A, Cooper C, Francis R, Kanis JA, Marsh D, McCloskey EV, Reid DM, Selby P, Wilkins M, National Osteoporosis Guideline Group (NOGG) (2009) Guidelines for the diagnosis and management of osteoporosis in postmenopausal women and men from the age of 50 years in the UK. Maturitas 62 (2):105-108

16. Rabenda V, Vanoverloop J, Fabri V, Mertens R, Sumkay F, Vannecke C, Deswaef A, Verpooten GA, Reginster JY (2008) Low incidence of anti-osteoporosis treatment after hip fracture. Bone Joint Surg Am 90(10):2142-2148

17. Jennings LA, Auerbach AD, Maselli J, Pekow PS, Lindenauer PK, Lee SJ (2010) Missed opportunities for osteoporosis treatment in patients hospitalized for hip fracture. J Am Geriatr Soc 58:650-657

18. Olofsson B, Stenvall M, Lundstrom M et al (2007) Malnutrition in hip fracture patients: an intervention study. J Clin Nurs 16:2027-2038

19. Salminen H, Saaf M, Johansson SE et al (2006) Nutritional status, as determined by the mini-nutritional assessment, and osteoporosis: a cross-sectional study of an elderly female population. Eur J Clin Nutr 60:486-493

20. Darling AL, Millward DJ, Torgerson DJ, Hewitt CE, LanhamNew SA (2009) Dietary protein and bone health: a systematic review and meta-analysis. Am J Clin Nutr 90(6):1674-1692

21. Peters BS, Martini LA (2010) Nutritional aspects of the prevention and treatment of osteoporosis. Arq Bras Endocrinol Metabol 54(2):179-185

22. Misra D, Berry SD, Broe KE, McLean RR, Cupples LA, Tucker KL, Kiel DP, Hannan MT (2010) Does dietary protein reduce hip fracture risk in elders? The Framingham osteoporosis study. Osteoporos Int. doi:10.1007/s00198-010-1179-4

23. Parfitt AM, Gallagher JC, Heaney RP, Johnston CC, Neer R, Whedon GD (1982) Vitamin D and bone health in the elderly. Am J Clin Nutr 36:1014-1031

24. Gallagher JC, Riggs BL, Eisman J, Hamstra A, Arnaud SB, DeLuca HF (1979) Intestinal calcium absorption and serum vitamin D metabolites in normal subjects and osteoporotic patients: effect of age and dietary calcium. J Clin Invest 64:729-736

25. Pattanaungkul S, Riggs BL, Yergey AL, Vieira NE, O'Fallon WM, Khosla S (2000) Relationship of intestinal calcium absorption to 1, 25-dihydroxyvitamin D [1, 25(OH)2D] levels in young versus elderly women: evidence for age-related intestinal resistance to 1,25(OH)2D action. J Clin Endocrinol Metab 85:4023-4027

26. Lips P (2001) Vitamin D deficiency and secondary hyperparathyroidism in the elderly: consequences for bone loss and fractures and therapeutic implications. Endocr Rev 22:447-450

27. Dawson-Hughes B, Heaney RP, Holick MF, Lips P, Meunier PJ, Vieth R (2005) Estimates of optimal vitamin D status. Osteoporos Int 16:713-716 
28. Finch S, Doyle W, Lowe C, Bates CJ, Prentice A, Smithers G, Clarke PC (1998) National diet and nutrition survey: people aged 65 years and over. volume 1: report of the diet and nutrition survey. The Stationary Office, London

29. Looker AC, Pfeiffer CM, Lacher DA, Schleicher RL, Picciano MF, Yetley EA (2008) Serum 25-hydroxyvitamin D status of the US population:1988-1994 compared with 2000-2004. Am J Clin Nutr 88:1519-1527

30. Lu L, Yu Z, Pan A, Hu FB, Franco OH, Li H, Li X, Tang X, Chen Y, Lin X (2009) Diab Care 32(7):1278-1283

31. Wat WZ, Leung JY, Tam S, Kung AW (2007) Prevalence and impact of vitamin D insufficiency in southern Chinese adults. Ann Nutr Metab 51(1):59-64

32. Chapuy MC, Arlot ME, Duboeuf F, Brun J, Crouzet B, Arnaud S, Delmas PD, Meunier PJ (1992) Vitamin D3 and calcium to prevent hip fractures in elderly women. N Engl J Med 327:16371642

33. Porthouse J, Cockayne S, King C, Saxon L, Steele E, Aspray T, Baverstock M, Birks Y, Dumville J, Francis RM, Iglesias C, Puffer S, Sutcliffe A, Watt I, Torgerson DJ (2005) Randomized controlled trial of calcium and supplementation with cholecalciferol (vitamin D3) for prevention of fractures in primary care. BMJ 330(7498):1003-1006

34. Brant AM, Avenell A, Campbell MK, McDonald AM, Maclenan GS, McPherosn GC et al (2005) Oral vitamin D3 and calcium for secondary prevention of low- trauma fractures in elderly people (Randomized Evaluation of Calcium Or Vitamin D, RECORD) a randomized placebo-controlled trial. Lancet 365(9471):1621-1628

35. Jackson RD, LaCroix AZ, Gass M, Wallace RB, Robbins J, Lewis CE, Bassford T, Beresford SAA, Black HR, Blanchette P, Bonds DE, Brunner RL, Brzyski RG, Caan B, Cauley JA, Chlebowski RT, Cummings SR, Granek I, Hays J, Heiss G, Hendrix SL, Howard BV, Hsia J, Hubbell FA, Johnson KC, Judd H, Kotchen JM, Kuller LH, Langer RD, Lasser NL, Limacher MC, Ludlam S, Manson JE, Margolis KL, McGowan J, Ockene JK, O'Sullivan MJ, Phillips L, Prentice RL, Sarto GE, Stefanick ML, Van Horn L, Wactawski-Wende J, Whitlock E, Anderson GL, Assaf AR, Barad D (2006) Calcium plus vitamin D supplementation and the risk of fractures. N Engl J Med 354(7):669-683

36. Tang BMP, Eslick GD, Nowsan C, Smith C, Tang BMP, Eslick GD, Nowsan C, Smith C, Bensoussan (2007) Use of calcium or calcium in combination with vitamin $\mathrm{D}$ supplementation to prevent fractures and bone loss in people aged 50 years and older: a meta -analysis. Lancet 370:657-666

37. Avenell A, Gillespie W, Gillespie L, O'Connell D (2009) Vitamin $\mathrm{D}$ and vitamin $\mathrm{D}$ analogues for preventing fractures associated with involutional and postmenopausal osteoporosis. Cochrane Database Syst Rev 2(2):CD000227

38. Boonen S, Lips P, Bouillon R, Bischoff-Ferrari HA, Vanderschueren D, Haemtjens P (2007) Need for additional calcium to reduce the risk of hip fracture with vitamin D supplementation: evidence from a comparative metaanalysis of randomized controlled trials. J Clin Endocrinol Metab 92:1415-1423

39. Bischoff-Ferrari HA, Willet WC, Wong JB, Stuck AE, Staehelim HB, Oray JE, Thoma A, Kiel DP, Henschkowski J (2009) Prevention of nonvertebral fractures with oral vitamin D and dose dependency, a meta-analysis of randomized controlled trials. Arch Intern Med 169(6):551-561

40. Bischoff-Ferrari HA, Dawson-Hughes B, Baron JA, Burckhardt P, Li R, Spiegelman D, Specker B, Orav JE, Wong JB, Staehelin HB, O'Reilly E, Kiel DP, Willett WC (2007) Calcium intake and hip fracture risk in men and women: a metaanalysis of prospective cohort studies and randomized controlled trials. Am J Clin Nutr 86:1780-1790

41. Bolland MJ, Barber PA, Doughty RN, Mason B, Horne A, Ames R, Gamble GD, Grey A, Reid I (2008) Vascular events in healthy older women receiving calcium supplementation: randomised controlled trial. BMJ 336:262-266

42. Parkkari J, Kannus P, Palvanen M, Natri A, Vainio J, Aho H, Vuori I, Jarvinen M (1999) Majority of hip fractures occur as a result of a fall and impact on the greater trochanter of the femur: a prospective controlled hip fracture study with 206 consecutive patients. Calcif Tissue Int 65(3):183-187

43. Youm T, Koval KJ, Kummer FJ, Zuckerman JD (1999) Do all hip fractures result from a fall? Am J Orthop 28(3):190-194

44. Mosekilde L (2005) Vitamin D and the elderly. Clin Endocrinol $62: 265-281$

45. Venning G (2005) Recent developments in vitamin D deficiency and muscle weakness among elderly people. Br Med J 330:524-526

46. Visser M, Deeg DJ, Lips P (2003) Low vitamin D and high parathyroid hormone levels as determinants of loss of muscle strength and muscle mass (sarcopenia): the longitudinal aging study Amsterdam. J Clin Endocrinol Metab 88:5766-5772

47. Bischoff-Ferrari HA, Dietrich T, Orav EJ, Hu FB, Zhang Y, Karlson EW, Dawson-Hughes B (2004) Higher 25-hydroxyvitamin D concentrations are associated with better lower-extremity function in both active and inactive persons aged $\geq 60 \mathrm{y}$. Am J Clin Nutr 80:752-758

48. Kuchuk NO, Pluijm SMF, Schoor NM, Looman CWN, Smit JH, Lips P (2009) Relationships of serum 25-hydroxyvitamin D to bone mineral density and serum parathyroid hormone and markers of bone turnover in older persons. J Clin Endocrinol Metab 94:1244-1250

49. Snijder MB, van Schoor NM, Pluijm SM, van Dam RM, Visser M, Lips P (2006) Vitamin D status in relation to one-year risk of recurrent falling in older men and women. J Clin Endocrinol Metab 91:2980-2985

50. Pfeifer M, Begerow B, Minne HW (2002) Vitamin D and muscle function. Osteoporos Int 13:187-194

51. Gillespie LD, Robertson MC, Gillespie WJ, Lamb SE, Gates S, Cumming RG, Rowe BH (2009) Interventions for preventing falls in older people living in the community. Cochrane Database Syst Rev. Issue 2:CD007146

52. Bischoff-Ferrari HA, Dawson-Hughes B, Staehelin NB, Orav JE, Theiler R, Wong JB, Egli A, Kiel DP, Henschkowski J (2009) Fall prevention with supplemental and active forms of vitamin D: a metaanalysis of randomised controlled trials. Br Med J 339:b3692

53. Trivedi DP, Doll R, Khaw KT (2003) Effect of four monthly oral vitamin D3 (cholecalciferol) supplementation on fractures and mortality in men and women living in the community randomised double blind controlled trial. Br Med J 326:469-472

54. Smith H, Anderson F, Raphael H, Crozier S, Cooper C (2004) Effect of annual intramuscular vitamin D supplementation on fracture risk: population-based, randomised, double blind, placebo-controlled trial. Osteoporos Int 15(suppl 1):S8

55. Sanders KM, Stuart AL, Williamson EJ, Simpson JA, Kotowicz YD, Nicholson GC (2010) Annual high-dose oral vitamin D and falls and fractures in older women: a randomized controlled trial. JAMA 303(18):1815-1822

56. Sato Y, Manabe S, Kuno H, Oizumi K (1999) Amelioration of osteopenia and hypovitaminosis D by 1-alpha-hydroxyvitamin D3 in elderly patients with Parkinson's disease. J Neurol Neurosurg Psychiatry 66:64-68

57. Shiraki M, Kushida K, Yamazaki K, Nagai T, Inoue T, Orimo H (1996) Effects of 2 years' treatment of osteoporosis with 1alphahydroxy vitamin D3 on bone mineral density and incidence of fracture: a placebo-controlled, double-blind prospective study. Endocr J 43(2):211-220

58. North American Menopause Society (2010) Estrogen and progestogen use in postmenopausal women: 2010 position statement of The North American Menopause Society. Menopause 17:242-255

59. Cranney A, Tugwell P, Zytaruk N et al (2002) Meta-analysis of calcitonin for the treatment of postmenopausal osteoporosis. Endocr Rev 23:540-551 
60. Lyles KW, Colón-Emeric CS, Magaziner JS et al (2007) Zoledronic acid in reducing clinical fracture and mortality after hip fracture. N Engl J Med 357:1799-1809

61. Colón-Emeric CS, Mesenbrink P, Lyles KW et al (2010) Potential mediators of the mortality reduction with zoledronic acid after hip fracture. J Bone Miner Res 25:91-97

62. Black DM, Delmas PD, Eastell R et al (2007) Once-yearly zoledronic acid for treatment of postmenopausal osteoporosis. $\mathrm{N}$ Engl J Med 356:1809-1822

63. Boonen S, McClung MR, Eastell R, El-Hajj Fuleihan G, Barton IP, Delmas P (2004) Safety and efficacy of risedronate in reducing fracture risk in osteoporotic women aged 80 and older: implications for the use of antiresorptive agents in the old and oldest old. J Am Geriatr Soc 52:1832-1839

64. Ensrud KE, Black DM, Palermo L et al (1997) Treatment with alendronate prevents fractures in women at highest risk: results from the fracture intervention trial. Arch Intern Med 157:26172624

65. Seeman E, Vellas B, Benhamou C et al (2006) Strontium ranelate reduces the risk of vertebral and nonvertebral fractures in women eighty years of age and older. J Bone Miner Res 21:1113-1120

66. Reginster JY, Seeman E, De Vernejoul MC et al (2005) Strontium ranelate reduces the risk of nonvertebral fractures in postmenopausal women with osteoporosis: Treatment of Peripheral Osteoporosis (TROPOS) study. J Clin Endocrinol Metab 90:2816-2822

67. Boonen S, Marin F, Mellstrom D, Xie L, Desaiah D, Krege JH, Rosen CJ (2006) Safety and efficacy of teriparatide in elderly women with established osteoporosis: bone anabolic therapy from a geriatric perspective. J Am Geriatr Soc 54:782-789

68. Cranney A, Tugwell P, Zytaruk N (2002) Meta-analyses of therapies for postmenopausal osteoporosis. IV Meta-analysis of raloxifene for the prevention and treatment of postmenopausal osteoporosis Endocr Rev 23:524-528

69. Silverman SL, Christiansen C, Genant HK et al (2008) Efficacy of bazedoxifene in reducing new vertebral fracture risk in postmenopausal women with osteoporosis: results from a 3-year, randomized, placebo-, and active controlled clinical trial. J Bone Miner Res 23:1923-1934

70. Cummings SR, San Martin J, McClung MR et al (2009) Denosumab for prevention of fractures in postmenopausal women with osteoporosis. N Engl J Med 361:756-765

71. McDonald MM, Schindeler A, Little DG (2007) Bisphosphonate treatment and fracture repair. BoneKEy-Osteovision 4:236-251

72. Cao Y, Mori S, Mashiba T et al (2002) Raloxifene, estrogen, and alendronate affect the processes of fracture repair differently in ovariectomized rats. J Bone Miner Res 17:2237-2246

73. Rozental TD, Vazquez MA, Chacko AT, Ayogu N, Bouxsein ML (2009) Comparison of radiographic fracture healing in the distal radius for patients on and off bisphosphonate therapy. J Hand Surg Am 34:595-602

74. Alkhiary YM, Gerstenfeld LC, Krall E, Westmore M, Sato M, Mitlak BH, Einhorn TA (2005) Enhancement of experimental fracture-healing by systemic administration of recombinant human parathyroid hormone (PTH 1-34). J Bone Joint Surg Am 87:731741

75. Nakajima A, Shimoji N, Shiomi K, Shimizu S, Moriya H, Einhorn TA, Yamazaki M (2002) Mechanisms for the enhancement of fracture healing in rats treated with intermittent low- dose human parathyroid hormone (1-34). J Bone Miner Res 17:2038-2047

76. Andreassen TT, Ejersted C, Oxlund H (1999) Intermittent parathyroid hormone (1-34) treatment increases callus formation and mechanical strength of healing rat fractures. J Bone Miner Res 14:960-968

77. Li YF, Luo E, Feng G, Zhu SS, Li JH, Hu J (2009) Systemic treatment with strontium ranelate promotes tibial fracture healing in ovariectomized rats. Osteoporos Int. doi:10.1007/s00198-009-1140-6

78. Habermann B, Kafchitsas K, Olender G, Augat P, Kurth A (2010) Strontium ranelate enhances callus strength more than PTH 1-34 in an osteoporotic rat model of fracture healing. Calcif Tissue Int $86: 82-89$

79. Goldhahn J, Little D, Mitchell P et al (2010) Evidence for antiosteoporosis therapy in acute fracture situations - recommendations of a multidisciplinary workshop of the international society for fracture repair. Bone 46:267-271

80. Giangregorio L, Papaioannou A, Cranney A, Zytaruk N, Adachi JD (2006) Fragility fractures and the osteoporosis care gap: an international phenomenon. Semin Arthritis Rheum 35:293-305

81. Cramer JA, Gold DT, Silverman SL, Lewiecki EM (2007) A systematic review of persistence and compliance with bisphosphonates for osteoporosis. Osteoporos Int 18:1023-1031

82. Bolland MJ, Grey AB, Gamble GD, Reid IR (2010) Effect of osteoporosis treatment on mortality: a meta-analysis. J Clin Endocrinol Metab 95:1174-1181

83. Khosla S, Amin S, Orwoll E (2008) Osteoporosis in men. Endocr Rev 29:441-464

84. Neuman MD, Archan S, Karlawish JH, Schwartz JS, Fleisher LA (2009) The relationship between short-term mortality and quality of care for hip fracture: a meta-analysis of clinical pathways for hip fracture. Am Geriatr Soc 57(11):2046-2054

85. Bruyere O, Brandi ML, Burlet N, Harvey N, Lyritis G, Minne H, Boonen S, Reginster JY, Rizzoli R, Akesson K (2008) Postfracture management of patients with hip fracture: a perspective. Curr Med Res Opin 24(10):2841-2851

86. Fried LP, Tangen CM, Walston J et al (2001) Cardiovascular health study collaborative research group. J Gerontol A Biol Sci Med Sci 56:M146-M156

87. Moayyeri A (2008) The association between physical activity and osteoporotic fractures: a review of the evidence and implications for future research. Ann Epidemiol 18(11):827-835

88. Li F, Harmer P, Fisher KJ et al (2005) Tai Chi and fall reductions in older adults: a randomized controlled trial. J Gerontol A Biol Sci Med Sci 60:187-194

89. Robertson MC, Campbell AJ, Gardner MM et al (2002) Preventing injuries in older people by preventing falls: a metaanalysis of individual-level data. J Am Geriatr Soc 50:905-911

90. Verschueren SM, Roelants M, Delecluse C et al (2004) Effect of 6-month whole body vibration training on hip density, muscle strength, and postural control in postmenopausal women: a randomized controlled pilot study. J Bone Miner Res 19:352-359

91. Parker MJ, Gillespie WJ, Gillespie LD (2005) Hip protectors for preventing hip fractures in older people. Cochrane Database Syst Rev 3:CD001255

92. Parker MJ, Gillespie WJ, Gillespie LD (2006) Effectiveness of hip protectors for preventing hip fractures in elderly people: systematic review. BMJ 332:571-574 